\title{
HÁ DESIGUALDADE DE PODER ENTRE OS ESTADOS E REGIÕES DO BRASIL? UMA ABORDAGEM UTILIZANDO O ÍNDICE DE PODER DE BANZHAF E A PENROSE SQUARE ROOT LAW
}

\author{
Ana Carolina da Cruz lima * \\ Francisco de Sousa Ramos ${ }^{\dagger}$
}

\begin{abstract}
Resumo
No Brasil sempre se discute sobre o número de representantes na Câmara Federal, com indicações de sub ou sobre-representatividade. Esta discussão tem valor político e econômico, pois uma parcela dos recursos públicos é definida nesta instância, sendo influenciada pelo efetivo poder estadual, que pode ser mensurado pelo Índice de Banzhaf. Uma proposta, sugerida por Penrose, é analisada para as UF's e regiões brasileiras. A aplicação mostra que, tanto para o atual sistema quanto para o proposto, a região Sudeste é a mais favorecida. Em relação aos Estados, os mais desenvolvidos e populosos possuem maior poder de voto em ambas situações.
\end{abstract}

Palavras-chave: Distribuição regional de recursos; Desigualdades regionais; Índice de Poder de Banzhaf; Lei de Penrose

\begin{abstract}
In Brazil there are always discussions about the number of representatives in the Federal Camera, with indications of sub or super representativeness. This discussion has political and economic value because an amount of the public resources is defined in this body and it can be linked to the effective power of the states, which can be measured by the Banzhaf index. A proposal, suggested by Penrose, is analyzed for Brazilian States and Regions. Application shows that, for the current as for the Penrose system, the most favored region is the Southeast. From the viewpoint of States, it is noticed that are those more developed and populous that possess larger voting power in both situations.
\end{abstract}

Keywords: Regional distribution of resources; Regional inequality; Banzhaf Power Index; Penrose's Law

JEL classification: $\mathrm{O} 18, \mathrm{C} 72, \mathrm{D} 72$

\footnotetext{
* Doutoranda em Economia (CEDEPLAR/UFMG) - Bolsista CNPq. Rua Artur Campelo, 71, Areias - 50.780-060 - Recife, PE. Email: ana_carolinacl@yahoo.com

† Departamento de Economia/PIMES - UFPE; pesquisador do CNPq. Email:fsr@ufpe.br
} 


\section{Introdução}

A transferência de recursos constitucionais e voluntários do Governo Federal para as esferas sub-nacionais de governo (macrorregiões, Estados e municípios) é de fundamental importância para a análise do desenvolvimento regional, pois a implementação de muitos projetos sócio-econômicos está diretamente relacionada a estas liberações. Além disso, a escassez de recursos disponíveis para a realização destas transferências implica em intensa disputa estadual/regional, traduzida pelos longos debates na Câmara dos Deputados, instância na qual são determinadas, em alguma medida, as diretrizes e os objetivos do Orçamento da União. Durante esse processo de alocação de recursos, os deputados federais formam blocos (coalizões) estaduais/regionais com o objetivo de destinar maior parcela dos gastos públicos definidos no Orçamento para seus respectivos Estados/regiões, independente de sua filiação partidária. A formação destas coalizões tem gerado comentários recorrentes no cenário político nacional referentes a problemas de sub ou sobrerepresentatividade na Câmara Federal, com grandes consequências sobre a distribuição dos recursos públicos, como citado em reportagem da Folha de São Paulo em 03/02/2007:

"A distribuição do número de deputados por Estado distorce a representação popular e é fator gerador de crises políticas e descrédito da Câmara. A sub-representação dos Estados do Sudeste e do Sul e a sobre-representação do Norte, Nordeste e Centro-Oeste, acabam enfraquecendo o Legislativo" (Villa, M. A., A "nova Câmara" será melhor que a anterior?).

Esta discussão sobre intensidade do poder dos Estados e regiões envolve não apenas aspectos políticos, mas também econômicos, pois estar sobre ou sub-representado na Câmara Federal pode significar que um determinado Estado/região obtenha maiores ou menores benefícios.

É justamente este argumento que está sendo utilizado por algumas lideranças para defender uma mudança no sistema de representatividade, atualmente definido por um critério populacional combinado a limites inferiores e superiores no número de deputados que cada Estado deve ter. Tais lideranças se sentem prejudicadas pelo sistema vigente e defendem a idéia de que os Estados mais populosos são prejudicados pelo mesmo. Abriu-se, assim, espaço para uma rediscussão do atual sistema, bem como sua avaliação e os possíveis benefícios e/ou prejuízos que o mesmo pode trazer para os Estados em particular e para o país como um todo.

Os estudos mais recentes enfocando esta discussão se referem à União Européia (por exemplo, Zyczkowski \& Stomczunski (2004) e Algaba et al. (2001), entre outros). No Brasil o assunto foi abordado por Novaes \& Rosenblatt (1991), ao apresentar alternativas para que o sistema reflita mais rigorosamente a realidade, considerando mais fortemente o critério populacional. Outro estudo é o de Jatobá \& Ramos (2003) em que, utilizando o Valor de Shapley, calculam índices de representatividade na Câmara Federal entre 1945 e 1998, concluindo que se deve ser cauteloso no que se refere aos critérios essencialmente populacionais.

Assim sendo, a discussão de critérios é essencial para verificar questões de representatividade, bem como a verificação sobre a alocação dos recursos federais. 
Portanto, o objetivo deste trabalho é obter o Índice de Poder de Banzhaf para os Estados e regiões brasileiras de acordo com o critério atual, verificando se o mesmo é representativo ou não. Ademais, utiliza-se o critério definido por Penrose, no qual o peso de cada Estado/região deve ser aproximadamente proporcional à raiz quadrada de sua população, o que atenua, em certa medida, o desequilíbrio existente em relação ao número de cidadãos que cada Estado/região possui. Comparações entre os dois critérios são então realizadas.

A seção 2 faz um breve relato sobre as disparidades regionais e a distribuição de recursos, seguido de uma discussão, na seção 3, sobre o Sistema Orçamentário Nacional e a divisão de poder entre os Estados e regiões do Brasil. A seção 4 descreve o instrumental teórico utilizado para o cálculo dos índices. Na seção 5 o índice de Poder de Banzhaf é calculado e na seção 6 são realizadas as considerações finais.

\section{Desigualdades Regionais e Distribuição de Recursos Federais}

\subsection{Desigualdades Regionais: o Produto Interno Bruto}

Segundo dados do IBGE, a participação relativa da região Sudeste no Produto Interno Bruto (PIB) nacional diminuiu entre 1995 e 2006 (de 58,7\% para $56,8 \%$ ), mas esta região ainda é a principal responsável pela dinâmica econômica do país, seguida da região Sul $(16,3 \%)$. As demais regiões tiveram um pequeno aumento em suas participações, mas ainda assim estão muito abaixo da região Sudeste (a participação conjunta das mesmas aumentou de 23,4\% em 1995 para 26,9\% em 2006), conforme dados da tabela 1:

De forma geral, os dados sobre o PIB demonstram que a configuração regional da economia brasileira, apesar das melhorias alcançadas nos últimos anos, como a implantação de um parque industrial relativamente diversificado na região Nordeste e a expansão do agronegócio na região Centro-Oeste, manteve-se praticamente inalterada, com as regiões Sudeste e Sul continuando a contribuir de forma mais significativa para a dinâmica e o crescimento do país.

\subsection{Desigualdades Regionais: as Transferências da União}

A ausência de instrumentos nacionais de políticas de desenvolvimento regional concedeu às Transferências da União para os Estados e municípios importante papel para a manutenção e/ou estímulo da dinâmica econômica em determinadas regiões do país, visto que, em muitos casos, estas representam a principal fonte de recursos da unidade subnacional. Dentre as principais Transferências da União destacam-se as Transferências Constitucionais, em especial o Fundo de Participação dos Estados e do Distrito Federal (FPE), o Fundo de Participação dos Municípios (FPM) e o Fundo de Manutenção e Desenvolvimento do Ensino Fundamental e de Valorização do Magistério (FUNDEF). O FPE e o FPM constituem importante instrumento de redistribuição da renda nacional, visto que estes promovem a transferência de parcela dos recursos arrecadados em áreas mais desenvolvidas para regiões menos desenvolvidas do país: $85 \%$ dos recursos são destinados aos Estados das regiões Norte $(25,37 \%)$, Nordeste $(52,46 \%)$ e Centro-Oeste $(7,17 \%)$ e $15 \%$ aos Estados das regiões Sul $(6,52 \%)$ e Sudeste $(8,48 \%)$. 
Tabela 1: Participação das Grandes Regiões no Produto Interno Bruto do Brasil - 1995-2006

\begin{tabular}{lrrrrrr}
\hline & 1995 & 1996 & 1997 & 1998 & 1999 & 2000 \\
\hline Norte & 4,6 & 4,6 & 4,4 & 4,5 & 4,4 & 4,6 \\
Nordeste & 12,8 & 13,2 & 13,1 & 13,1 & 13,1 & 13,1 \\
Sudeste & 58,7 & 58,1 & 58,6 & 58,2 & 58,2 & 57,8 \\
Sul & 17,9 & 18,0 & 17,7 & 17,5 & 17,7 & 17,6 \\
Centro-Oeste & 6,0 & 6,1 & 6,2 & 6,8 & 6,4 & 7,0 \\
\hline Brasil & 100 & 100 & 100 & 100 & 100 & 100 \\
\hline \multicolumn{7}{c}{} \\
& 2001 & 2002 & 2003 & 2004 & 2005 & 2006 \\
\hline Norte & 4,8 & 5,0 & 5,0 & 5,3 & 5,0 & 5,1 \\
Nordeste & 13,1 & 13,5 & 13,8 & 14,1 & 13,1 & 13,1 \\
Sudeste & 57,1 & 56,3 & 55,2 & 54,9 & 56,5 & 56,8 \\
Sul & 17,8 & 17,7 & 18,6 & 18,2 & 16,6 & 16,3 \\
Centro-Oeste & 7,2 & 7,4 & 7,5 & 7,5 & 8,9 & 8,7 \\
\hline Brasil & 100 & 100 & 100 & 100 & 100 & 100 \\
\hline Fonte: IBGE - Diretoria de Pesquisas, Coordenação de Contas Nacionais.
\end{tabular}

As demais Transferências da União, chamadas Transferências Voluntárias por representarem um repasse de recursos correntes ou de capital a outro ente da Federação, a título de cooperação que não decorra de determinação constitucional ou legal, também constituem importante parcela da receita estadual/municipal. Por este motivo é interessante verificar se um Estado/região recebe proporcionalmente à sua população mais ou menos recursos voluntários da União. Para tanto foi calculado um coeficiente de alocação de recursos que relaciona a distribuição percentual das Transferências Voluntárias com a distribuição percentual da população brasileira. Quando este for maior que 1, significa que um Estado/região recebe proporcionalmente mais recursos da União; quando for menor que 1, tem-se a situação oposta. Na tabela 2 observa-se que no período 1997-2007 as regiões Norte, Nordeste e CentroOeste apresentaram coeficientes de alocação maiores que 1, em detrimento das regiões Sul e Sudeste.

Em relação aos Estados, verifica-se que nas regiões Norte e Nordeste todos os Estados tinham coeficientes, em média, maiores que 1, bem como na região Centro-Oeste, com exceção do Distrito Federal, enquanto nas regiões Sul e Sudeste os Estados apresentaram coeficientes menores que 1, exceto Santa Catarina. Quando são adicionadas as Transferências Constitucionais a este cálculo, mantém-se o mesmo comportamento, exceção feita ao Estado do Espírito Santo que passa a ter coeficiente maior que 1 e aos Estados de Goiás e Santa Catarina que têm seus coeficientes reduzidos para valores menores do que 1 i (ver tabela A.1). Este fato parece evidenciar a preocupação implícita nas Transferências da União no que diz respeito às disparidades regionais.

Em relação à distribuição percentual das Transferências Totais da União, de acordo com dados do Ministério da Fazenda - Secretaria do Tesouro Nacional -, a região que mais recebe verbas da União é a Nordeste e a mesma ocupa esta posição desde 1997, entretanto, a sua participação sofreu redução 


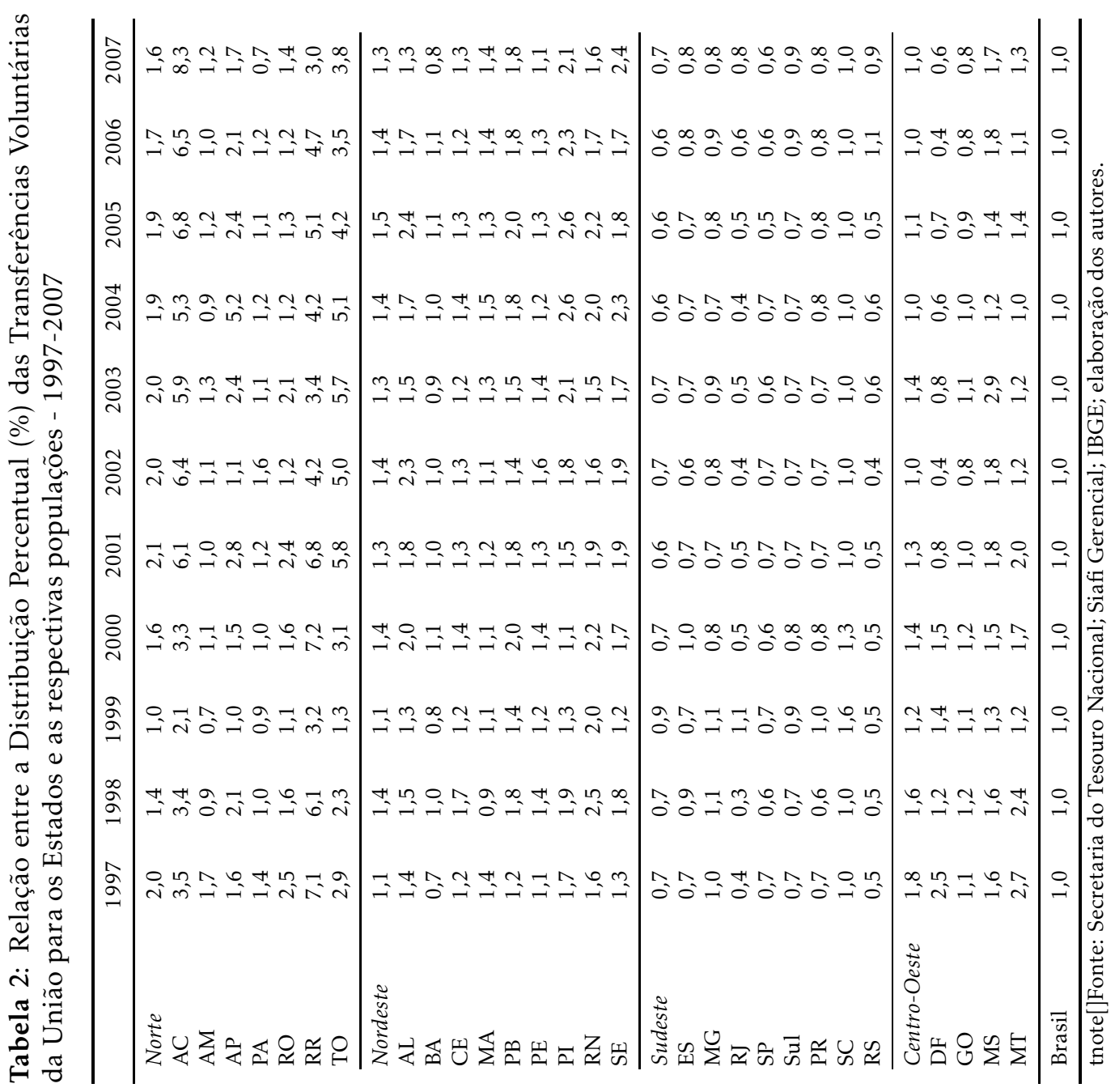


no período em análise (queda de aproximadamente 22,2\%). A região Sudeste teve um aumento de 37,5\% em sua participação relativa entre 1997 e 2007, passando a ocupar a segunda posição no ranking nacional em detrimento da região Norte, que teve uma redução de $20,3 \%$.

As demais regiões tiveram um pequeno aumento em suas participações relativas, mas este não foi suficiente para alterar a posição das mesmas. De forma geral, tanto em 1997 quanto em 2007, as regiões menos desenvolvidas do país, Norte e Nordeste, foram as que mais receberam Transferências da União. A participação dos Estados nordestinos é bastante homogênea, única exceção feita ao Estado da Bahia (recebe aproximadamente 20,7\% das transferências destinadas à região por ano). Na região Sudeste, São Paulo e Minas Gerais são os maiores receptores das Transferências da União, sendo responsáveis, em média, por $80 \%$ do total de transferências destinadas à região a cada ano (respectivamente, $52,4 \%$ e $28,4 \%$ em 2007). Nas regiões Norte, Sul e Centro-Oeste a situação é um pouco mais equilibrada, com algumas exceções, como o Pará (situação mais favorável) e o Distrito Federal (situação menos favorável).

A análise em separado das Transferências Voluntárias da União mostra que, para o período 1997-2007, a região que teve maior participação relativa no total nacional foi a Nordeste, seguida da região Sudeste, ou seja, o padrão de distribuição é mantido. Esta distribuição de recursos pela União é um ponto que gera inúmeras discussões no cenário nacional, uma vez que os Estados/regiões que mais contribuem para a arrecadação nacional nem sempre são os maiores beneficiados pela mesma.

De acordo com dados do Ministério da Fazenda para o período 1995/2006, os Estados da região Sudeste são os que mais contribuem para a arrecadação dos impostos federais $(71,1 \%$ em 2006). Em seguida vêm os Estados das regiões Sul e Centro-Oeste (esta aumentou sua participação entre 1995 e 2006, aproximando-se dos indicadores da região Sul, mas este fato está relacionado, principalmente, ao comportamento da arrecadação no Distrito Federal). As regiões Norte e Nordeste tiveram uma pequena redução em suas participações durante o período analisado e em 2006 representavam apenas 7,4\% da arrecadação dos impostos e contribuições federais.

A justificativa para a distribuição das Transferências da União reside no desigual nível de desenvolvimento das regiões brasileiras, ou seja, no fato de as Transferências levarem em conta não apenas a arrecadação de cada Estado/região, mas também os desníveis de renda entre os mesmos. Segundo dados do Instituto de Economia Aplicada (IPEA) para 2005, as regiões Nordeste e Norte têm parcela significativa de seus habitantes vivendo abaixo da linha de pobreza e muitos dos Estados nordestinos têm índices superiores a $50 \%$, chegando a $60 \%$ nos Estados de Alagoas e Maranhão. Para estas regiões como um todo, os percentuais sofreram reduções, mas na região Norte alguns Estados tiveram aumento no mesmo (Acre, Roraima, Amazonas, Amapá e Rondônia). As demais regiões progrediram neste indicador e estão abaixo da média nacional (31\%). O Estado com menor parcela da população vivendo abaixo da linha de pobreza é Santa Catarina (10\% em 2005).

Vale destacar que, apesar da redução da participação direta do Estado na economia a partir de 1990 (Araújo 2000), as Transferências da União continuam a representar importante parcela dos orçamentos estaduais/municipais. Além das Transferências asseguradas pela Constituição, resta aos Estados e regiões discutir, no âmbito do Congresso Nacional, a elaboração do Orçamento 
da União, com o intuito de atrair mais recursos para a consecução de seus respectivos objetivos.

\section{O Orçamento da União e a Divisão de Poder entre as Unidades da Federação}

O Sistema Orçamentário Brasileiro (SOB) está definido nos artigos 165 a 169 da Constituição da República Federativa do Brasil, promulgada em 05 de Outubro de 1988. O mesmo é composto por três instrumentos principais: a Lei Orçamentária Anual (LOA), a Lei de Diretrizes Orçamentárias (LDO) e o Plano Plurianual (PPA) ${ }^{1}$.

Este Sistema tem três dimensões: i) jurídica: o orçamento público tem caráter e força de lei e define limites a serem respeitados pelos governantes e agentes públicos - no tocante à realização de despesas e à arrecadação de receitas; ii) econômica: o orçamento público é basicamente o instrumento por meio do qual o governo extrai recursos da sociedade e os injeta em áreas selecionadas, o que auxilia a redistribuição de recursos na sociedade; e iii) política: se o orçamento público tem um caráter redistributivo, o processo de elaboração, aprovação e gestão do orçamento embute necessariamente perspectivas e interesses conflitantes que se resolvem em última instância no âmbito da ação política dos agentes públicos e dos inúmeros segmentos sociais.

É justamente a dimensão política do SOB que evidencia a importância da representação de cada unidade federada no Congresso Nacional, em especial na Câmara Federal: os agentes pertencentes à mesma são os representantes dos cidadãos de seus respectivos Estados e desejam tornar consistentes seus projetos políticos pessoais.

O sistema de representatividade dos Estados brasileiros é definido pela Constituição Federal (Art. 45, §1 ${ }^{\circ}$ ): “o número total de deputados, bem como a representação por Estado e pelo Distrito Federal, será estabelecido por lei complementar, proporcionalmente à população, procedendo-se aos ajustes necessários, no ano anterior às eleições, para que nenhuma daquelas Unidades da Federação tenha menos de oito ou mais de setenta deputados". ${ }^{2}$ Ou seja, o critério adotado para a representação de cada unidade federativa na Câmara Federal é baseado em sua população, com ressalvas nos limites inferiores e superiores no número de deputados.

A discussão sobre a representatividade dos Estados/regiões na Câmara Federal ganha cada vez mais espaço no Brasil, uma vez que nesta instância são tomadas importantes decisões, como o já citado Orçamento da União. Em geral, prevalece a idéia de que o atual sistema favorece alguns Estados/regiões em detrimento dos demais.

Vários estudos têm analisado o link entre o número de representantes e o efetivo poder de cada Estado/região representado. Alguns deles são aplicados à União Européia, como Algaba et al. (2001) e Bilbao et al. (2000). Um trabalho particularmente interessante é o de Zyczkowski \& Stomczunski (2004).

\footnotetext{
${ }^{1}$ O PPA tem duração de quatro anos e estabelece os objetivos da administração federal para as despesas de capital e os programas de duração continuada, funcionando como um planejamento de médio prazo. A LDO é elaborada anualmente e objetiva detalhar as prioridades para o ano subseqüente e orientar a elaboração da LOA, que deverá estimar as receitas e fixar as despesas da administração pública federal para o ano seguinte. Os projetos de leis relativos a estes três instrumentos devem ser apreciados pelo Congresso Nacional.

${ }^{2}$ Para maiores detalhes ver Lei Complementar no 78 de 30/12/1993.
} 
Eles consideram que alguns sistemas de votação no âmbito do Conselho Europeu (Treaty of Nice e The Proposition of The European Convent - The Draft of the European Constitution) não são representativos, uma vez que cidadãos de diferentes países não têm a mesma influência sobre a decisão tomada pelo mesmo. As indagações levantadas pelos autores são as seguintes: i) a influência de um Estado/região sobre as decisões tomadas pela Câmara é realmente proporcional ao número de votos que o mesmo possui? ii) um aumento no número de votos de um Estado/região que faz parte da Câmara sempre causa um aumento no seu poder de voto? iii) num sistema onde os pesos designados para cada Estado/região são proporcionais a sua população, a influência de cada cidadão do Estado/região sobre a tomada de decisão é a mesma? iv) o sistema é democrático e representativo? v) é possível construir um sistema de votos objetivo que seja simples, representativo e eficaz? ${ }^{3}$

Por este motivo, Zyczkowski \& Stomczunski (2004) propõem uma solução baseada na Lei de Penrose, a qual condiciona os pesos de cada país à raiz quadrada da sua população com o intuito de obter um sistema simples, representativo, transparente, eficaz e objetivo. Tais considerações são interessantes e o trabalho tem características que podem ser aplicadas à realidade brasileira.

Num país como o Brasil, no qual a desigualdade entre as regiões é bastante significativa, é de fundamental importância garantir o equilíbrio de poder e representatividade entre os Estados/regiões, sendo esta uma forma de minimizar, ou pelo menos não aumentar, as disparidades existentes. Este fato demonstra o quão importante é o papel desempenhado pelo atual sistema de divisão de poder, e este é o principal motivo que nos leva a analisá-lo, verificando suas vantagens e desvantagens.

\section{Teoria dos Jogos e Poder de Voto}

A Teoria dos Jogos Cooperativos constitui num bom instrumental de análise para responder às questões acima, dado que ela permite construir uma série de índices que permitem calcular o poder de voto de agentes individuais. Os participantes deste processo de tomada de decisão podem ser pessoas, grupos de pessoas, países, etc. No problema em questão os participantes são os Estados/regiões que compõem a Câmara Federal.

\subsection{O Índice de Poder de Banzhaf}

Um sistema de votação ponderado é aquele no qual os participantes podem ter número de votos distintos e o poder de cada participante no sistema de votação se mede por sua capacidade para influir nas decisões. A representação matemática deste jogo cooperativo é:

$$
\left[q ; w\left(v_{1}\right), w\left(v_{2}\right), \ldots, w\left(v_{n}\right)\right],
$$

onde $v_{i}$ representa o votante $i, w\left(v_{i}\right)$ é o número de votos (peso) que cada votante possui, e $q$ é a quota, ou seja, o número de votos necessários para aprovar uma proposta.

\footnotetext{
${ }^{3}$ Um sistema de votação simples é aquele no qual apenas um critério é adotado para definir o peso (o número de votos) de cada participante; representativo é um sistema no qual a influência dos cidadãos é a mais equilibrada possível; e o mesmo é eficaz se o resultado da eleição corresponde ao desejo da maioria (Zyczkowski \& Stomczynski, 2004).
} 
Um conjunto de votantes que se unem para votar a favor ou contra uma proposta forma uma coalizão. Esta coalizão será vencedora se a soma de seus votos (pesos) for maior ou igual à quota. Da mesma forma, uma coalizão será de bloqueio se a soma de seus votos (pesos) é suficiente para conseguir que uma medida não seja aprovada. Caso contrário, será uma coalizão perdedora. Um conceito importante é o de votante crítico, ou seja, quando este se retira de uma coalizão vencedora (ou de bloqueio), esta deixa de sê-lo.

Um votante/jogador é um agente que possui um interesse específico. Ele será chamado ditador quando tiver todo o poder de decisão, e será chamado jogador dummy quando não tiver influência alguma sobre o processo.

Neste trabalho, todos os Estados de uma região do país são considerados um único jogador, pois os mesmos podem atuar como uma coalizão para aprovar medidas que favoreçam seu eleitorado. Esta é uma abordagem útil, mesmo não ocorrendo usualmente, pois permite calcular o poder relativo de cada região do país.

Como já evidenciado em trabalhos anteriores (Zyczkowski \& Stomczunski 2004), o poder de um jogador não é necessariamente proporcional ao número de votos que o mesmo possui. Então, como determinar este poder efetivo?

Em 1946, Lionel S. Penrose propôs um índice para calcular o poder de voto de um jogador (Penrose Index). Para tanto, é preciso calcular todas as combinações possíveis que um jogador pode utilizar para formar uma coalizão com outros jogadores a fim de conseguir a maioria qualificada. John Banzhaf III realizou análise similar à de Penrose para sistemas de votos em blocos baseado em análises probabilísticas, popularizando este método que ficou mais conhecido como o Índice de Poder de Banzhaf.

Assim sendo, o poder de um jogador se define como sua capacidade de influir nas decisões aprovadas mediante um jogo de votação ponderada. Os índices buscam medir, a priori, este poder, baseados na capacidade de cada jogador para participar das coalizões vencedoras. É uma medida de poder, portanto, mais precisa do que o número de votos que o jogador possui.

\subsection{Algoritmos para o Cálculo do Índice de Poder de Banzhaf}

\section{Algoritmo de Zyczkowski \& Stomczynski}

Zyczkowski \& Stomczunski (2004) descrevem um algoritmo capaz de computar o Índice de Poder Banzhaf, considerando os seguintes elementos:

- $n$ jogadores representados numa assembléia;

- o número de todas as coalizões possíveis, $2^{n}$, com idêntica probabilidade de ocorrer;

- o número total de coalizões vencedoras, $\omega$, satisfazendo a regra da maioria;

- há $2^{n-1}$ diferentes coalizões em que um jogador pode participar;

- o número de coalizões vencedoras que incluem o jogador $x$ é $\omega_{x}$;

- $\eta_{x}=2 \omega_{x}-\omega$ é o número de vezes que o jogador $x$ é crítico para uma coalizão. 
O Índice Absoluto de Banzhaf é dado pela probabilidade de $x$ ser crítico,

$$
\mathrm{B}_{x}=\eta_{x} / 2^{n-1},
$$

com um valor normalizado de

$$
\beta_{x}=\eta_{x} / \sum_{x} \eta_{x}
$$

Se $x$ é ditador, $\beta_{x}=1$; se é dummy, $\beta_{x}=0$.

Para calcular a eficiência de um sistema utiliza-se o Índice de Coleman, que é igual à probabilidade de uma coalizão satisfazer a regra da maioria:

$$
A=w / 2^{n}
$$

Algoritmo com funções geratrizes (Bilbao et al. 2000) (Bilbao et al, 2000)

Um jogo de votação ponderada se define como um conjunto finito de $N$ jogadores. Cada jogador $i \in N, i=1,2, \ldots, n$, tem um número de votos $w_{i}>0$. Cada coalizão de jogadores, $s \subseteq N$, reúne a soma dos votos de seus componentes dada por

$$
w(s)=\sum_{i \in s} w_{i}
$$

Dada uma quota $q$ necessária para aprovar decisões, diz-se que uma coalizão $s$ é vencedora se $w(s) \geq q$ e é perdedora se $w(s)<q$, ou seja, existem duas possibilidades para cada coalizão:

$$
v(s)= \begin{cases}1 & \text { se } w(s) \geq q \\ 0 & \text { caso contrário }\end{cases}
$$

Portanto, o jogo é totalmente representado por: $v \equiv\left[q ; w_{1}, w_{2}, \ldots, w_{n}\right] \quad$ (4) .

As funções geratrizes permitem contar as coalizões que cumprem determinadas propriedades. Elas proporcionam um método para contar o número de elementos $c(k)$ de um conjunto, quando tais elementos possuem uma determinada configuração dependente de uma variável $k$. Dada uma sucessão $\{c(k)\}_{k \geq 0}$, sua função geratriz é uma série de potências

$$
f(x)=\sum_{k \geq 0} c(k) x^{k}
$$

Para calcular o Índice de Banzhaf deve-se encontrar o número de coalizões para as quais o jogador $i$ é decisivo, dado por

$$
\eta_{i}(v)=\sum_{k=q-w_{i}}^{q-1} b_{k}^{i}
$$

onde $i$ é o número de coalizões $s \subseteq N$ tais que $i \notin s$ e $w_{i}=k$. A soma entre $q-w_{i}$ e $q-1$ fornece o número total de coalizões perdedoras que se tornaram vencedoras ao incorporar o jogador $i$. A seguinte função geratriz permite calcular estes números: 


$$
B_{i}(x)=\prod_{j-1, j \neq i}^{n}\left(1+x^{w_{j}}\right)=\sum_{k=0}^{w n / i} b_{k}^{i} x^{k}
$$

O número total de coalizões para as quais os jogadores são decisivos é dado por

$$
\eta(v)=\sum_{i \in n} \eta_{i}(v)
$$

e o Índice de Banzhaf é

$$
\beta_{i}=\eta_{i}(v) / \eta(v)
$$

\section{O Índice de Poder de Banzhaf para os Estados e Regiões do Brasil}

Uma hipótese essencial, adotada a partir de agora, é que todas as votações que ocorrem na Câmara Federal têm a presença de todos os seus membros. Isto pode ser visto como uma limitação; entretanto, quando há assuntos importantes, como a alocação de recursos através do Orçamento da União, na pauta de votação, a presença dos membros da Câmara tem sido elevada, devido à importância que este tipo de votação possui frente aos projetos políticos de cada parlamentar. ${ }^{4}$

O procedimento legislativo é definido da seguinte forma: os votos são medidos por pesos, que refletem a população de cada Estado/região. A Câmara Federal é composta por 513 deputados, que estão distribuídos de acordo com a tabela 3. A proposta é aprovada se a soma dos pesos dos membros que votam

\begin{tabular}{|c|c|c|c|c|c|}
\hline Estado & Deputados & Estado & Deputados & Estado & Deputados \\
\hline $\mathrm{AC}$ & 8 & MA & 18 & ES & 10 \\
\hline $\mathrm{AM}$ & 8 & $\mathrm{~PB}$ & 12 & MG & 53 \\
\hline $\mathrm{AP}$ & 8 & PE & 25 & RJ & 46 \\
\hline PA & 17 & PI & 10 & SP & 70 \\
\hline $\mathrm{RO}$ & 8 & $\mathrm{RN}$ & 8 & Sudeste & 179 \\
\hline $\mathrm{RR}$ & 8 & SE & 8 & GO & 17 \\
\hline TO & 8 & Nordeste & 151 & MS & 8 \\
\hline Norte & 65 & PR & 30 & MT & 8 \\
\hline $\mathrm{AL}$ & 9 & RS & 31 & DF & 8 \\
\hline $\mathrm{BA}$ & 39 & SC & 16 & Centro-Oeste & 41 \\
\hline $\mathrm{CE}$ & 22 & Sul & 77 & Brasil & 513 \\
\hline
\end{tabular}
a favor é maior ou igual a 257.

Tabela 3: Número de Deputados por Estados e Regiões no Brasil

Fonte: Site da Câmara Federal

A seguir, serão calculados os Índices de Poder de Banzhaf para os Estados e Regiões do Brasil, considerando a situação atual e o sistema sugerido por Penrose.

\footnotetext{
${ }^{4}$ ver Regimento Interno da Câmara dos Deputados do Brasil.
} 


\subsection{O Índice de Poder de Banzhaf para as Regiões Brasileiras}

Sistema Atual: Peso baseado no critério populacional, com limites inferiores e superiores no número de deputados

Neste caso, os elementos do problema são:

- $n=5$

- soma total dos pesos = 513;

- $q=257$;

- $2^{n}=2^{5}=32$;

- $2^{n-1}=2^{4}=16$;

- $\omega=16$, portanto, $\omega_{N}=10, \omega_{N e}=12, \omega_{S}=10, \omega_{S e}=12 \mathrm{e} \omega_{C o}=10$;

- $\eta_{N}=4, \eta_{N e}=8, \eta_{S}=4, \eta_{S e}=8$ e $\eta_{C o}=4$;

- $\mathrm{A}=0,5=50 \%$.

Tabela 4: Índice de Poder de Banzhaf por região - Sistema Atual

\begin{tabular}{lrccccc}
\hline Região $(x)$ & Peso & $\omega_{x}$ & $\omega-\omega_{x}$ & $\eta_{x}=\omega_{x}-\omega$ & $B_{x}=\frac{\eta_{x}}{x^{n-1}}$ & $\beta_{x}=\frac{\eta_{x}}{\sum_{x} \eta_{x}}$ \\
\hline Norte & 65 & 10 & 6 & 4 & 0,25 & $\approx 0,14$ \\
Nordeste & 151 & 12 & 4 & 8 & 0,50 & $\approx 0,14$ \\
Sul & 77 & 10 & 6 & 4 & 0,25 & $\approx 0,14$ \\
Sudeste & 179 & 12 & 4 & 8 & 0,50 & $\approx 0,14$ \\
Centro-Oeste & 41 & 10 & 6 & 4 & 0,25 & $\approx 0,14$ \\
\hline
\end{tabular}

Fonte: Site da Câmara Federal; elaboração dos autores.

A tabela 4 mostra que as regiões Sudeste e Nordeste têm índices iguais a 0,29 , enquanto as regiões Sul, Norte e Centro-Oeste têm índices iguais a 0,14 . Assim, os índices demonstram que um critério populacional beneficia as regiões mais populosas, e o sistema, de uma forma geral, não equilibra o poder e a representatividade das regiões na Câmara Federal. O sistema não atende às indagações colocadas na seção 3 do presente trabalho, referentes à proporcionalidade dos votos e à representatividade. Entretanto, vale salientar que, se não fossem os limites estabelecidos no número de deputados que cada Estado pode ter, esta situação poderia ser ainda mais desequilibrada.

\section{Sistema Proposto por Penrose: Peso proporcional à raiz quadrada da população das regiões}

Num processo de eleições indiretas, a influência de um cidadão sobre a decisão final depende do produto do poder de voto durante as eleições diretas. É claro que quanto mais populoso um país, menor será a influência de um cidadão sobre a decisão. Penrose, através do que ficou conhecido como Penrose Square Root Law, estabelece que a influência de cada cidadão de um país sobre o resultado da eleição será a mesma se o poder de voto de cada Estado/região for aproximadamente proporcional à raiz quadrada do número de cidadãos do mesmo (the first square-root-rule) e, ao mesmo tempo, adotando este tipo 
Tabela 5: Índice de Poder de Banzhaf para as regiões brasileiras - Peso de cada jogador é proporcional à raiz quadrada de sua população

\begin{tabular}{lcccc}
\hline Região & População & $\begin{array}{c}\text { Raiz Quadrada } \\
\text { da População }\end{array}$ & $\begin{array}{c}\text { Peso } \\
(\%)\end{array}$ & $\begin{array}{c}\beta_{i} \\
(\%)\end{array}$ \\
\hline Norte & 12.900 .704 & $3.591,76$ & 13,09 & 11 \\
Nordeste & 47.741 .711 & $6.909,54$ & 25,19 & 26 \\
Sul & 25.107 .616 & $5.010,75$ & 18,27 & 19 \\
Sudeste & 72.412 .411 & $8.509,55$ & 31,02 & 33 \\
Centro-Oeste & 11.636 .728 & $3.411,26$ & 12,43 & 11 \\
\hline
\end{tabular}

Fonte: IBGE; elaboração dos autores.

de peso será possível reduzir ao mínimo a probabilidade de uma decisão ir contra o desejo da maioria (the second square-root-rule).

Adotando estas medidas é possível corrigir o sistema atual? Em geral, a solução ótima deve atender às seguintes condições: o sistema de votos deve ser tão simples quanto possível, objetivo (ou seja, baseado em princípios científicos e não em barganha política), efetivo e transparente, sendo os pesos escolhidos de forma a assegurar que o sistema é representativo.

Neste caso os elementos do problema são:

- $n=5$

- $q=51 \%$;

- $2^{n}=2^{5}=32$;

- $2^{n-1}=2^{4}=16$;

- $\omega=15$, portanto, $\omega_{N}=9, \omega_{N e}=11, \omega_{S}=10, \omega_{S e}=12$ e $\omega_{C o}=9$;

- $\eta_{N}=3, \eta_{N e}=7, \eta_{S}=5, \eta_{S e}=9$ e $\eta_{C o}=3$;

- $A=46,88 \%$.

Pode-se observar, a partir da tabela 5, que há uma redistribuição dos pesos de cada região que favorece a mais populosa e "equilibra" a distribuição do poder entre as demais. O Índice de Poder de Banzhaf da região Sudeste sobe de $29 \%$ para $33 \%$, enquanto os índices das regiões Norte e Centro-Oeste caem de $14 \%$ para $11 \%$. O Nordeste também tem uma queda de poder (de $29 \%$ para $26 \%$ ) e o Sul é beneficiado com um aumento de 5 pontos percentuais.

Para calcular o poder de voto de um cidadão utiliza-se o seguinte indicador:

$$
\mu_{i}=\beta_{i}\left(k_{d}\right)^{1 / 2} / \beta_{d}\left(k_{i}\right)^{1 / 2} \quad(5),
$$

onde $d$ representa a região mais populosa e $k$ a população. Então:

Percebe-se que no sistema proposto por Penrose há uma distribuição mais eqüitativa do poder de voto entre os cidadãos das diferentes regiões: o voto de um cidadão da região mais populosa tem peso igual a 1, enquanto a influência dos cidadãos das demais regiões se estabelece um pouco abaixo desta, com a região Norte tendo o indicador mais baixo $(0,79)$. Caso oposto ao do sistema atual, no qual os cidadãos da região mais populosa e desenvolvida - Sudeste - têm menor influência, seguidos da região Sul, enquanto os cidadãos das regiões Norte, Centro-Oeste e Nordeste têm peso maior que um, chegando a 1,23 no último caso. 
Tabela 6: Poder de voto de um cidadão por região

\begin{tabular}{lcc}
\hline \multirow{2}{*}{ Região } & $\mu_{i}$ & $\mu_{i}$ \\
& Sistema Atual & Sistema Proposto \\
\hline Norte & 1,14 & 0,79 \\
Nordeste & 1,23 & 0,97 \\
Sul & 0,82 & 0,98 \\
Sudeste & 1,00 & 1,00 \\
Centro-Oeste & 1,20 & 0,83 \\
\hline
\end{tabular}

Fonte: IBGE; elaboração dos autores.

\subsection{O Índice de Poder de Banzhaf para os Estados Brasileiros}

Sistema Atual - Peso baseado no critério populacional, combinado a limites inferiores e superiores no número de deputados

Neste caso os elementos do problema são:

$-n=27$

- soma total dos pesos = 513;

- $q=257$

- $2^{n}=2^{27}=134.217 .728$;

- $2^{n-1}=2^{26}=67.108 .864$.

Tabela 7: Índice de Poder de Banzhaf por Estado - Sistema Atual

\begin{tabular}{|c|c|c|c|c|c|}
\hline UF & Peso & $\begin{array}{l}\text { Indice de } \\
\text { Poder de } \\
\text { Banzhaf } \\
-\beta_{x}(\%)\end{array}$ & UF & Peso & $\begin{array}{l}\text { Indice de } \\
\text { Poder de } \\
\text { Banzahf } \\
-\beta_{x}(\%)\end{array}$ \\
\hline $\mathrm{AC}$ & 8 & 1,51 & $\mathrm{RN}$ & 8 & 1,51 \\
\hline $\mathrm{AM}$ & 8 & 1,51 & $\mathrm{SE}$ & 8 & 1,51 \\
\hline $\mathrm{AP}$ & 8 & 1,51 & PR & 30 & 5,75 \\
\hline PA & 17 & 3,22 & RS & 31 & 5,95 \\
\hline $\mathrm{RO}$ & 8 & 1,51 & SC & 16 & 3,03 \\
\hline $\mathrm{RR}$ & 8 & 1,51 & ES & 10 & 1,88 \\
\hline $\mathrm{TO}$ & 8 & 1,51 & MG & 53 & 10,5 \\
\hline $\mathrm{AL}$ & 9 & 1,70 & RJ & 46 & 9,02 \\
\hline BA & 39 & 7,56 & SP & 70 & 15,0 \\
\hline CE & 22 & 4,19 & GO & 17 & 3,22 \\
\hline MA & 18 & 3,41 & MT & 8 & 1,51 \\
\hline PB & 12 & 2,32 & MS & 8 & 1,51 \\
\hline $\mathrm{PE}$ & 25 & 4,76 & DF & 8 & 1,51 \\
\hline PI & 10 & 1,88 & & & \\
\hline
\end{tabular}

Fonte: Site da Câmara Federal; elaboração dos autores.

Os Estados mais desenvolvidos do país, São Paulo, Minas Gerais e Rio de Janeiro possuem índices bem elevados quando comparados à média nacional, respectivamente 15,0, 10,5 e 9,02, seguidos dos Estados da região Sul, Paraná $(5,75)$ e Rio Grande do Sul $(5,95)$. Fora destas duas regiões, apenas o Estado da 
Bahia tem índice superior a $5(7,56)$, mais um fato que evidencia a diferença de poder em relação aos Estados mais atrasados do país. Ou seja, assim como para as regiões, os índices demonstram que este critério beneficia os Estados mais populosos, que apresentam, em geral, maior nível de desenvolvimento, e o sistema, de uma forma geral, não equilibra o poder e a representatividade entre os mesmos.

Sistema Proposto por Lionel S. Penrose - Peso proporcional à raiz quadrada da população

Neste caso os elementos do problema são:

- $n=27$;

- $q=51 \%$

- $2^{n}=2^{27}=134.217 .728$;

- $2^{n-1}=2^{26}=67.108 .864$

Tabela 8: Índice de Poder de Banzhaf por Estado - Peso de cada jogador é proporcional à raiz quadrada de sua população

\begin{tabular}{|c|c|c|c|c|}
\hline UF & População & $\begin{array}{c}\text { Raiz Quadrada } \\
\text { da População }\end{array}$ & $\begin{array}{c}\text { Peso } \\
(\%)\end{array}$ & $\begin{array}{l}\beta_{i} \\
(\%)\end{array}$ \\
\hline $\mathrm{AC}$ & 557.526 & 746,68 & 1 & 0,99 \\
\hline AM & 2.812 .557 & $1.677,07$ & 3 & 2,99 \\
\hline $\mathrm{AP}$ & 477.032 & 690,68 & 1 & 0,99 \\
\hline PA & 6.192 .307 & $2.488,43$ & 4 & 4,00 \\
\hline RO & 1.379 .787 & $1.174,64$ & 2 & 1,98 \\
\hline $\mathrm{RR}$ & 324.397 & 569,56 & 1 & 0,99 \\
\hline TO & 1.157 .098 & $1.075,68$ & 2 & 1,98 \\
\hline $\mathrm{AL}$ & 2.822 .621 & $1.680,07$ & 3 & 2,99 \\
\hline $\mathrm{BA}$ & 13.070 .250 & $3.615,28$ & 6 & 6,08 \\
\hline $\mathrm{CE}$ & 7.430 .661 & $2.725,92$ & 5 & 5,03 \\
\hline MA & 5.651 .475 & $2.377,28$ & 4 & 4,00 \\
\hline $\mathrm{PB}$ & 3.443 .825 & $1.855,75$ & 3 & 2,99 \\
\hline $\mathrm{PE}$ & 7.918 .344 & $2.813,96$ & 5 & 5,03 \\
\hline PI & 2.843 .278 & $1.686,20$ & 3 & 2,99 \\
\hline $\mathrm{RN}$ & 2.776 .782 & $1.666,37$ & 3 & 2,99 \\
\hline $\mathrm{SE}$ & 1.784 .475 & $1.335,84$ & 2 & 1,98 \\
\hline PR & 9.563 .458 & $3.092,48$ & 5 & 5,03 \\
\hline RS & 10.187 .798 & $3.191,83$ & 5 & 5,03 \\
\hline SC & 5.356 .360 & $2.314,38$ & 4 & 4,00 \\
\hline ES & 3.097 .232 & $1.759,90$ & 3 & 2,99 \\
\hline MG & 17.891 .494 & $4.229,83$ & 7 & 7,17 \\
\hline RJ & 14.391 .282 & $3.793,58$ & 6 & 6,08 \\
\hline SP & 37.032 .403 & $6.085,43$ & 10 & 10,80 \\
\hline GO & 5.003 .228 & $2.236,79$ & 4 & 4,00 \\
\hline MT & 2.504 .353 & $1.582,51$ & 3 & 2,99 \\
\hline MS & 2.078 .001 & $1.441,53$ & 2 & 1,98 \\
\hline $\mathrm{DF}$ & 2.051 .146 & $1.432,18$ & 2 & 1,98 \\
\hline
\end{tabular}

Fonte: IBGE - Censo Demográfico 2000; elaboração dos autores. 
Ao contrário do que é observado quando consideramos uma região agindo sempre como um único jogador, a mudança de critério do ponto de vista estadual é capaz de redistribuir o poder entre os jogadores, diminuindo o percentual dos Estados mais desenvolvidos (São Paulo: cai de 15\% para 10,8\%, Minas Gerais: de 10,5\% para 7,17\%, Rio Grande do Sul: de 5,95\% para 5,03\%), bem como o índice da Bahia (cai de 7,56\% para 6,08\%), aumentando, quase que de forma generalizada, o percentual dos demais Estados, porém estes ainda se situam em patamares muito inferiores, com poucas exceções, como Ceará e Pernambuco (sobem de $4,19 \%$ e $4,76 \%$ para $5,03 \%$ e 5,03\%, respectivamente), que também são Estados que têm maior dinâmica econômica na região Nordeste.

No sistema proposto por Penrose, também há melhor distribuição do poder de voto entre os cidadãos: a tabela 9 mostra que os cidadãos do Estado mais populoso, São Paulo, têm indicadores iguais a 1, bem como os cidadãos dos Estados de Alagoas, Amazonas e Piauí. Os cidadãos dos demais Estados têm indicadores próximos a este valor, em alguns casos os indicadores são um pouco maiores, como em Mato Grosso $(1,06)$, Tocantins e Ceará $(1,04)$, Pernambuco, Rio Grande do Norte e Goiás $(1,01)$; em outros são menores, por exemplo, Distrito Federal $(0,78)$, Mato Grosso do Sul $(0,77)$ e Acre $(0,75)$, sendo este último o menor indicador do país.

Tabela 9: Poder de voto de um cidadão por Estado

\begin{tabular}{ccccccc}
\hline UF & $\begin{array}{c}\mu_{i} \\
\text { atual }\end{array}$ & $\begin{array}{c}\mu_{i} \\
\text { proposto }\end{array}$ & & UF & $\begin{array}{c}\mu_{i} \\
\text { atual }\end{array}$ & $\begin{array}{c}\mu_{i} \\
\text { proposto }\end{array}$ \\
\cline { 1 - 2 } \cline { 5 - 6 } AC & 0,82 & 0,75 & & RN & 0,37 & 1,01 \\
AM & 0,37 & 1,00 & & SE & 0,46 & 0,84 \\
AP & 0,89 & 0,81 & & PR & 0,75 & 0,92 \\
PA & 0,52 & 0,91 & & RS & 0,76 & 0,89 \\
RO & 0,52 & 0,95 & & SC & 0,53 & 0,97 \\
RR & 1,08 & 0,98 & & ES & 0,43 & 0,96 \\
TO & 0,57 & 1,04 & & MG & 1,01 & 0,96 \\
AL & 0,41 & 1,00 & & RJ & 0,96 & 0,90 \\
BA & 0,85 & 0,95 & & SP & 1,00 & 1,00 \\
CE & 0,62 & 1,04 & & GO & 0,58 & 1,01 \\
MA & 0,58 & 0,95 & & MT & 0,39 & 1,06 \\
PB & 0,51 & 0,91 & & MS & 0,42 & 0,77 \\
PE & 0,69 & 1,01 & & DF & 0,43 & 0,78 \\
PI & 0,45 & 1,00 & & & \\
\hline
\end{tabular}

Fonte: IBGE; elaboração dos autores.

Neste caso, em que os Estados são considerados jogadores, o sistema proposto por Penrose é capaz por si só de provocar mudanças na estrutura de poder das regiões, chegando a resultados similares aos encontrados por Zyczkowski \& Stomczunski (2004) para a União Européia: o sistema é simples, objetivo e auxilia a equilibrar o poder entre os diferentes Estados brasileiros.

Vale salientar que, apesar dos questionamentos que surgem sobre o atual sistema de representação na Câmara Federal, ele ainda consegue minimizar em alguma medida as disparidades de poder entre as regiões brasileiras, devido principalmente a imposição dos limites inferiores e superiores no número de deputados que cada Estado deve ter. 


\subsection{Implicações para a Economia Nacional}

Além do Orçamento da União, muitos outros projetos de natureza econômica, essenciais para melhorar o ambiente produtivo nacional, são elaborados e decididos em primeira instância na Câmara Federal. Como exemplo, podemos citar as propostas, ainda sem apreciação no plenário da Câmara Federal, de regulamentação das Agências Reguladoras Nacionais, de reestruturação do Conselho Administrativo de Defesa Econômica (CADE), de regulamentação ambiental, de reforma tributária e de distribuição dos recursos oriundos da exploração de petróleo na camada do pré-sal. Estas propostas, se aprovadas, devem funcionar como sinalizadores para os agentes econômicos. No caso das Agências Reguladoras é fundamental a definição de um marco regulatório, pois as mesmas fiscalizam setores econômicos estratégicos para o desenvolvimento nacional, como o petrolífero. A reforma tributária é essencial para a dinamização da economia, dado seu potencial de desoneração da produção e do consumo. Já a divisão dos recursos da exploração de petróleo do pré-sal tem grande potencial para a redução das disparidades regionais (nova fonte de recursos da União). ${ }^{5}$

Entre os diversos projetos econômicos a serem discutidos e votados na Câmara Federal observa-se que aqueles que representam mais fielmente os interesses particulares de cada Estado/região têm maiores dificuldades de aprovação. A reforma tributária, que inclui a unificação das legislações estaduais do Imposto sobre Circulação de Mercadorias e Serviços (ICMS), é um ótimo exemplo para ilustrar esta situação. Além deste imposto representar importante fonte dos recursos estaduais, sua forma de tributação ${ }^{6}$ e a autonomia das legislações estaduais permitem que o mesmo seja utilizado como instrumento de política econômica, o que se constitui no principal argumento utilizado pelas lideranças políticas estaduais contra as propostas de reforma tributária encaminhadas pelo Ministério da Fazenda a Câmara Federal (PEC's 233/2008, $31 / 2007$ e $45 / 2007)$.

O debate político entre as unidades federadas inviabiliza a votação desta matéria: os Estados menos desenvolvidos do país (regiões Nordeste, Norte e Centro-Oeste) recusam-se a aceitar a alteração da forma de tributação, pois isto inviabilizaria a utilização deste imposto como instrumento de incentivo à dinâmica econômica local, e os Estados mais desenvolvidos (regiões Sul e Sudeste) também são contra esta modificação, pois a troca de princípio promoveria a alteração na distribuição dos recursos fiscais estaduais em detrimento dos mesmos (favoreceria os importadores líquidos do comércio interestadual - os Estados menos desenvolvidos). Em outras palavras, a aprovação da reforma tributária depende essencialmente dos impactos das propostas de mudanças do ICMS na arrecadação estadual.

Outra matéria que promete "esquentar" o debate político nacional e que terá grandes implicações sobre a dinâmica econômica do país está relacionada à distribuição dos recursos (royalties) oriundos da exploração do petróleo na camada do pré-sal ${ }^{7}$. No dia $1^{\circ}$ de Setembro de 2009 foram encaminhados a

\footnotetext{
${ }^{5}$ Esta discussão destacada na primeira edição do mês de Setembro da revista The Economist.

${ }^{6}$ O ICMS é cobrado no Estado de origem da produção de bens e serviços (Princípio da Origem), mesmo no caso em que toda a produção é exportada (Lima, 2008).

${ }^{7}$ No modelo atual de distribuição dos royalties do petróleo, $50 \%$ dos mesmos e as participações especiais são recolhidos à União, $40 \%$ aos Estados produtores e 10\% aos municípios produtores.
} 
Câmara Federal os projetos de lei relativos à exploração do petróleo na região do pré-sal e à criação da PETRO-SAL e do Fundo Social (PL n ${ }^{\circ}$ s 5.938, 5.939 e 5.940). Desde então, assiste-se um grande debate, iniciado pelo governador do Estado de Pernambuco, Eduardo Campos, sobre a distribuição dos ganhos desta produção entre os Estados brasileiros, antes mesmo de iniciada a atividade $^{8}$. Em uma série de entrevistas, o governador defendeu uma distribuição equitativa dos royalties de petróleo da camada do pré-sal entre todas as Unidades da Federação e não apenas entre aquelas onde estão localizadas as bacias de exploração (São Paulo, Rio de Janeiro e Espírito Santo), devido ao seu potencial de redução das disparidades regionais. Em entrevista ao portal G1 em 01/09/2009 Eduardo Campos declarou:

(o pré-sal) pode ser mais um instrumento de concentração regional ou pode ser um instrumento de equilíbrio econômico para o país como um todo. Não podemos fazer um debate regionalista atrasado. Mas também não podemos fazer um debate mesquinho e rasteiro. [...] se os recursos se concentrarem ali com os royalties, vai ter uma dupla concentração. Isso será ruim para o país e não só para o Nordeste.

E continuou: "eles (SP, RJ e ES) se articularam e aí nós resolvemos fazer uma articulação também", o que teria sido uma resposta a solicitação dos governadores destes três Estados ao presidente Luís Inácio Lula da Silva para a não alteração da distribuição destes recursos no novo marco regulatório da atividade petrolífera. Em entrevista ao site da revista Veja em 03/09/2009 Eduardo Campos ratificou sua posição e falou em nome dos Estados não produtores de petróleo: "Se for a velha regra do regionalismo, vamos ganhar não só na Câmara, como no Senado. Não é possivel existir uma regra que exclua a maioria do país".

Em resposta a estas declarações, o governador do Rio de Janeiro, Sérgio Cabral, saiu em defesa dos principais Estados produtores (São Paulo, Rio de Janeiro e Espírito Santo):

Eu acho que a distribuição de recursos cabe à União e ela faz isso muito bem. É assim que a União tem que trabalhar, com os recursos da União. O que a gente não concebe é fazer isso com recursos de um determinado Estado, porque aí você quebra o pacto federativo. [...] O Nordeste tem todo direito de pleitear os recursos da União, o que não pode é tirar recursos do Estado do Rio de Janeiro" (portal www.g1.com em 02/09/2009).

Evidenciado o caráter estadual das discussões acerca da reforma tributária e da distribuição dos recursos da exploração do petróleo na camada do pré-sal, podemos discutir como o sistema atual de votação da Câmara Federal e o proposto por Penrose podem determinar o resultado destas votações. Para simplificar a análise e considerando o "regionalismo" ainda existente no país iremos separar os Estados/regiões em dois grandes blocos que procuram direcionar os resultados: Sudeste e Nordeste. Estes dois blocos estabelecem suas posições, com o intuito de maximizar seus ganhos econômicos e a partir disto procuram influenciar os votos dos demais Estados/regiões. Desta forma

\footnotetext{
${ }^{8}$ O Deputado Federal José Guimarães (PT-CE) já tinha levantado este debate no plenário da Câmara Nacional durante a $200^{a}$ sessão ordinária em 12/08/2009. Todavia, esta discussão ganhou mais destaque na mídia nacional a partir das declarações dos governadores de Pernambuco e do Rio de Janeiro.
} 
e considerando os índices de poder de Banzhaf calculados anteriormente será possível discutir sobre os possíveis resultados destas matérias no plenário da Câmara Federal.

Primeiramente iremos analisar a problemática regional, cujos índices de poder de Banzhaf estão relacionados nas tabelas 4 e 5 .

No sistema atual de votação, observa-se que as regiões Sudeste e Nordeste possuem um poder de decisão de $29 \%$ cada uma, o que evidencia a importância das mesmas para o resultado da eleição, em outras palavras, a coalizão formada apenas pelas regiões Norte, Sul e Centro-Oeste nunca é vencedora, pois o poder de decisão da mesma é de apenas $42 \%$. Supondo que os interesses econômicos das regiões menos desenvolvidas sejam convergentes, podemos afirmar que Nordeste e Norte decidirão votar na mesma direção.

Similarmente, as regiões mais desenvolvidas, Sul e Sudeste, também decidirão votar em conjunto. Cada uma destas coalizões possui $43 \%$ do poder de decisão, logo, o resultado final da eleição dependerá da posição tomada pela região Centro-Oeste, pois as duas coalizões divergentes necessitam de seu voto para possuir a maioria, o que concede posição estratégica para esta região. Assim, do ponto de vista regional (e caracterizando de forma bastante acentuada as divergências entre os interesses das regiões mais e menos desenvolvidas do país) pode-se afirmar que o resultado da eleição dependerá do grau de convergência dos interesses econômicos da região Centro-Oeste em relação às demais regiões do país, tanto no que diz respeito à reforma tributária quanto à distribuição de royalties do pré-sal (neste último caso pode-se esperar que a região Centro-Oeste vote em conjunto com as regiões Norte e Nordeste). Vale salientar que a coalizão Nordeste-Sudeste sempre seria vencedora, pois possui $58 \%$ do poder de decisão, mas como estamos considerando situações nas quais os interesses econômicos destas regiões são divergentes é improvável que esta coalizão ocorra.

No sistema proposto, a coalizão Sul, Centro-Oeste e Norte também nunca é vencedora (possui $41 \%$ do poder de decisão). As regiões Sudeste e Nordeste possuem $33 \%$ e $26 \%$ do poder de decisão, respectivamente. Supondo, como anteriormente, que Nordeste e Norte votarão em conjunto, observa-se que esta coalizão possui $37 \%$ do poder de decisão, ou seja, necessita de mais votos para alcançar a maioria simples. Se as regiões Sul e Sudeste formam uma coalizão, elas obtêm um poder de decisão de $52 \%$, ou seja, elas formam uma coalizão que sempre será vencedora, independente dos votos das demais regiões. Mais ainda, a coalizão Norte, Nordeste e Centro-Oeste possui 48\% do poder de decisão e não consegue reverter o resultado da eleição. A única forma deste resultado ir de encontro à posição da região Sudeste seria se a região Sul resolvesse alterar o seu voto. Se, por exemplo, a reforma tributária beneficiasse estas duas regiões seria provável a aprovação da mesma no plenário da Câmara Federal sob este novo sistema de votação. No caso da distribuição dos royalties do pré-sal, o resultado dependeria da decisão tomada pela região Sul: se os benefícios econômicos resultantes da dinamização da economia da região Sudeste sobre a região Sul, por intermédio das cadeias produtivas e dos fluxos de comércio inter-regionais, forem considerados superiores aos ganhos relacionados a uma maior distribuição dos recursos do pré-sal, a proposta seria aprovada.

Passemos agora à análise da questão estadual, cujos índices de poder de Banzhaf estão relacionados nas tabelas 7 e 8.

No sistema atual de votação, a coalizão formada pelos Estados São Paulo, 
Minas Gerais, Rio de Janeiro, Bahia, Rio Grande do Sul e Paraná, tem 53,78\% do poder de decisão, ou seja, é uma coalizão vencedora em qualquer hipótese, pois possui a maioria simples. Projetos de natureza econômica que beneficiem estes Estados provavelmente serão aprovados.

Assim como no caso regional, vamos supor que os Estados das regiões Nordeste e Norte votam em conjunto, bem como os Estados das regiões Sul e Sudeste, formando duas coalizões com $41,12 \%$ e $51,73 \%$ do poder de decisão, respectivamente. Observa-se então que, do ponto de vista estadual, a coalizão Sul-Sudeste sempre é vencedora. Logo, assuntos de interesse destes Estados deveriam ser aprovados com certa "facilidade" na Câmara. Contudo, não é isto que se observa na prática, fato que provavelmente está relacionado à divergência entre os interesses econômicos dos mesmos. Por exemplo, se os representantes de Minas Gerais, Estado com grandes disparidades internas, decidem não votar com esta coalizão a mesma deixa de ser vencedora (seu poder de decisão cai para $41,23 \%$ ). Este pode ser o caso da reforma tributária e o mesmo aconteceria se qualquer outro Estado desta região decidisse por voto contrário. No caso da distribuição dos recursos do pré-sal, os Estados do Rio de Janeiro, São Paulo e Espírito Santo, os principais produtores, possuem $25,9 \%$ do poder de decisão. Se incluirmos Bahia ${ }^{9}$, Paraná e Santa Catarina, Estados com elevado potencial de exploração, este percentual sobe para $42,24 \%$, o que indica que a aprovação da manutenção da forma de distribuição destes recursos depende do voto de outros Estados (a posição de Minas Gerais seria estratégica neste sentido, pois tornaria esta coalizão vencedora). É preciso destacar também que uma coalizão formada pelos Estados das regiões Sul, Centro-Oeste e Norte nunca é vencedora, pois possui apenas $34,76 \%$ do poder de decisão.

No sistema proposto por Penrose, a coalizão formada pelos Estados das regiões Norte e Nordeste possui $48 \%$ do poder de decisão, enquanto a coalizão formada pelos Estados das regiões Sul e Sudeste possui 41,1\%, o que indica a posição estratégica e decisiva dos Estados da região central do Brasil: caso os mesmos, ou alguns deles, decidam votar de acordo com a coalizão formada pelas UF's das regiões Norte e Nordeste, uma vez que há maior probabilidade de seus interesses convergirem, temos uma coalizão vencedora. Uma coalizão formada por nove Estados (São Paulo, Minas Gerais, Rio de Janeiro, Bahia, Rio Grande do Sul, Paraná, Ceará, Pernambuco e qualquer outro) possui mais de $51 \%$ do poder de decisão, situação um pouco menos concentrada do que no sistema atual.

As mesmas dificuldades encontradas no sistema atual de votação para a aprovação da reforma tributária no país são encontradas no sistema proposto. O mesmo pode ser ressaltado em relação à distribuição dos recursos do présal, porém, os principais Estados produtores (Rio de Janeiro, São Paulo e Espírito Santo têm 19,87\% do poder de decisão; incluindo Bahia, Paraná e Santa Catarina o percentual aumenta para 34,98\%) necessitariam dos votos de outros Estados além de Minas Gerais.

Assim, considerada a complexidade da reforma tributária e a divergência entre os interesses estaduais, pode-se concluir que sob qualquer um dos sistemas de votação aqui considerados é difícil a sua aprovação. Já o caso do

\footnotetext{
${ }^{9}$ A Petrobrás iniciou a procura de petróleo na camada do pré-sal no litoral da Bahia, ainda sem resultados positivos. Contudo, já foram encontradas reservas de gás natural, o que pode estimular a exploração nesta área.
} 
pré-sal parece ser um pouco menos complicado, visto que a manutenção das taxas de distribuição dos royalties da exploração do petróleo da camada do pré-sal entre União, Estados e municípios, parece beneficiar pequena parcela do território nacional (em termos de investimentos diretos destes recursos). Por fim é preciso ressaltar que estes resultados são hipotéticos e a confirmação dos mesmos não necessariamente poderá ser verificada. Além disto, este processo demonstra como o jogo político atrasa a aprovação de matérias importantes para a economia nacional, contribuindo para o baixo dinamismo da mesma.

\section{Considerações Finais}

O sistema de representatividade vigente no Brasil, definido por uma combinação entre proporcionalidade populacional e limites inferiores e superiores no número de deputados por Estado, parece, à primeira vista, minimizar o desequilíbrio de poder entre as regiões. O cálculo do Índice de Poder de Banzhaf para as regiões brasileiras demonstra que são as regiões Sudeste e Nordeste, ou seja, as mais populosas do país, aquelas que têm maior influência no cenário nacional $\left(\beta_{i}=0,29\right)$. As demais regiões, Sul, Norte e Centro-Oeste, têm índices iguais a 0,14 e a distribuição de poder entre os cidadãos é bastante desigual.

Dada a forma de alocação de recursos no âmbito do Congresso Nacional, em especial na Câmara Federal, é importante que este sistema seja democrático, caso contrário, o mesmo pode auxiliar para aumentar as desigualdades existentes no país, uma vez que determinada(s) região(ões) pode $(\mathrm{m})$ sair prejudicada(s) do processo político.

Um sistema de representatividade alternativo foi proposto por Lionel Penrose. Ele sugere que o peso de cada Estado/região deve ser proporcional à raiz quadrada de sua população, pois desta forma, a influência de um cidadão em particular será mais equilibrada e será possível reduzir a probabilidade de uma decisão ir contra o desejo da maioria. O cálculo do Índice de Poder de Banzhaf para as regiões brasileiras demonstra que há um aumento de poder justamente das regiões mais desenvolvidas do país, Sul e Sudeste. Entretanto, quando este índice é calculado para os Estados, os resultados indicam que há uma distribuição mais eqüitativa de poder: há diminuição para os Estados mais desenvolvidos (São Paulo, Minas Gerais, Rio de Janeiro, Paraná, Rio Grande do Sul e Bahia) e aumento para os Estados mais pobres de forma quase que generalizada, apesar da distância ainda existente entre os mesmos. O peso dos cidadãos também tem melhor distribuição, isto é, a influência dos cidadãos em relação ao resultado da eleição é mais equilibrada, com o Estado mais populoso tendo indicador igual a 1.

Contudo, deve-se levar em consideração que o processo político é muito mais complexo do que uma análise superficial pode indicar. Em geral, nem sempre o número de votos de um Estado/região é proporcional ao poder de voto do mesmo. Há uma necessidade de reformulação das leis eleitorais para estabelecer o equilíbrio na Câmara Federal, visto que a utilização do critério populacional, seja direta ou indiretamente, inviabiliza a representação dos Estados menos populosos na mesma.

Dado que o processo de desenvolvimento do mercado interno brasileiro ocorreu de forma altamente desigual, estabelecendo diferentes níveis de de- 
senvolvimento entre suas regiões, é necessário buscar medidas que auxiliem na construção da federação. Talvez uma destas medidas seja que a distribuição de cadeiras na Câmara Federal não se baseie apenas na questão populacional, caso contrário, pode-se estabelecer uma representação política que incentive o aumento das desigualdades regionais (a região mais populosa - Sudeste é a mais desenvolvida do país; e os Estados mais desenvolvidos são os mais populosos - São Paulo, Minas Gerais, Rio de Janeiro, Rio Grande do Sul, Bahia e Paraná). Cabe aqui ressaltar que uma reavaliação do atual sistema de representatividade nacional poderia ter como ponto de partida justamente os níveis de desenvolvimento estaduais/regionais: à medida que os indicadores econômicos e sociais de um determinado Estado/região evoluíssem, os limites impostos no número de deputados por Estado poderiam ser revistos, o que estimularia a busca por melhores indicadores por parte das lideranças estaduais, visto que estes não resultariam em perdas de representantes para as mesmas. 


\section{Apêndice A}

Tabela A.1: Relação entre a distribuição percentual (\%) das Transferências da União para os Estados e as respectivas populações - 1997-2007

\begin{tabular}{|c|c|c|c|c|c|c|c|c|c|c|c|}
\hline & 1997 & 1998 & 1999 & 2000 & 2001 & 2002 & 2003 & 2004 & 2005 & 2006 & 2007 \\
\hline Norte & 2,9 & 2,2 & 2,1 & 2,1 & 2,1 & 2,2 & 2,2 & 2,2 & 2,2 & 2,3 & 2,2 \\
\hline $\mathrm{AC}$ & 8,3 & 5,8 & 5,4 & 5,6 & 5,8 & 6,1 & 6,0 & 6,0 & 6,0 & 6,1 & 6,1 \\
\hline AM & 1,4 & 1,3 & 1,3 & 1,3 & 1,4 & 1,4 & 1,4 & 1,4 & 1,4 & 1,4 & 1,4 \\
\hline AP & 10,2 & 7,2 & 6,7 & 6,8 & 7,0 & 7,2 & 7,0 & 7,1 & 6,9 & 6,9 & 6,9 \\
\hline PA & 1,8 & 1,4 & 1,2 & 1,2 & 1,2 & 1,2 & 1,1 & 1,2 & 1,2 & 1,2 & 1,2 \\
\hline $\mathrm{RO}$ & 2,7 & 2,0 & 2,0 & 2,1 & 2,1 & 2,3 & 2,3 & 2,2 & 2,4 & 2,4 & 2,5 \\
\hline $\mathrm{RR}$ & 10,6 & 7,7 & 7,3 & 7,6 & 7,7 & 8,0 & 7,9 & 7,5 & 7,8 & 7,8 & 7,6 \\
\hline TO & 5,0 & 3,6 & 3,5 & 3,6 & 3,8 & 3,9 & 3,9 & 3,7 & 4,0 & 4,1 & 4,2 \\
\hline Nordeste & 1,5 & 1,1 & 1,1 & 1,1 & 1,2 & 1,2 & 1,2 & 1,2 & 1,3 & 1,3 & 1,3 \\
\hline $\mathrm{AL}$ & 1,9 & 1,3 & 1,3 & 1,4 & 1,4 & 1,5 & 1,5 & 1,6 & 1,6 & 1,7 & 1,6 \\
\hline BA & 1,2 & 0,9 & 0,9 & 0,9 & 0,9 & 0,9 & 0,9 & 0,9 & 0,9 & 0,9 & 0,9 \\
\hline CE & 1,3 & 1,0 & 1,0 & 1,0 & 1,0 & 1,0 & 1,0 & 1,0 & 1,0 & 1,1 & 1,0 \\
\hline MA & 1,8 & 1,3 & 1,3 & 1,3 & 1,3 & 1,4 & 1,3 & 1,4 & 1,4 & 1,4 & 1,4 \\
\hline PB & 1,8 & 1,3 & 1,3 & 1,4 & 1,4 & 1,5 & 1,5 & 1,5 & 1,6 & 1,7 & 1,6 \\
\hline PE & 1,2 & 1,0 & 0,9 & 0,9 & 1,0 & 1,0 & 1,0 & 1,0 & 1,0 & 1,1 & 1,1 \\
\hline PI & 2,0 & 1,4 & 1,4 & 1,4 & 1,5 & 1,6 & 1,6 & 1,6 & 1,6 & 1,7 & 1,6 \\
\hline RN & 2,0 & 1,5 & 1,5 & 1,5 & 1,6 & 1,7 & 1,7 & 1,7 & 1,7 & 1,8 & 1,7 \\
\hline SE & 3,1 & 2,2 & 2,2 & 2,2 & 2,3 & 2,4 & 2,4 & 2,4 & 2,5 & 2,5 & 2,5 \\
\hline Sudeste & 0,4 & 0,7 & 0,8 & 0,8 & 0,7 & 0,7 & 0,7 & 0,7 & 0,6 & 0,6 & 0,7 \\
\hline ES & 1,1 & 1,2 & 1,2 & 1,1 & 1,2 & 1,1 & 1,1 & 1,2 & 1,2 & 1,1 & 1,1 \\
\hline MG & 0,6 & 0,8 & 0,8 & 0,8 & 0,7 & 0,7 & 0,7 & 0,7 & 0,7 & 0,7 & 0,8 \\
\hline RJ & 0,6 & 0,4 & 0,4 & 0,4 & 0,4 & 0,4 & 0,4 & 0,4 & 0,4 & 0,4 & 0,4 \\
\hline SP & 0,2 & 0,8 & 0,9 & 0,9 & 0,8 & 0,8 & 0,7 & 0,7 & 0,7 & 0,6 & 0,7 \\
\hline Sul & 0,8 & 1,0 & 0,9 & 0,9 & 0,9 & 0,9 & 0,9 & 0,9 & 0,9 & 0,9 & 0,8 \\
\hline PR & 0,9 & 0,9 & 0,9 & 0,8 & 0,8 & 0,8 & 0,8 & 0,9 & 0,9 & 0,9 & 0,9 \\
\hline SC & 0,8 & 0,9 & 0,9 & 0,9 & 0,9 & 0,9 & 0,9 & 0,9 & 0,9 & 0,9 & 0,8 \\
\hline RS & 0,7 & 1,0 & 0,9 & 0,9 & 0,9 & 0,9 & 0,9 & 0,9 & 0,9 & 0,8 & 0,8 \\
\hline Centro-Oeste & 1,0 & 0,9 & 0,9 & 0,9 & 0,9 & 1,0 & 1,0 & 1,0 & 1,0 & 1,0 & 1,0 \\
\hline DF & 0,5 & 0,3 & 0,3 & 0,4 & 0,4 & 0,4 & 0,4 & 0,4 & 0,5 & 0,4 & 0,4 \\
\hline GO & 0,8 & 0,9 & 0,8 & 0,9 & 0,9 & 0,9 & 0,9 & 1,0 & 0,9 & 0,9 & 0,9 \\
\hline MS & 1,3 & 1,0 & 1,0 & 1,0 & 1,0 & 1,1 & 1,1 & 1,1 & 1,1 & 1,2 & 1,2 \\
\hline MT & 1,7 & 1,3 & 1,3 & 1,4 & 1,3 & 1,3 & 1,4 & 1,5 & 1,6 & 1,5 & 1,5 \\
\hline Brasil & 1,0 & 1,0 & 1,0 & 1,0 & 1,0 & 1,0 & 1,0 & 1,0 & 1,0 & 1,0 & 1,0 \\
\hline
\end{tabular}

Fonte: Secretaria do Tesouro Nacional; Siafi Gerencial; IBGE; elaboração dos autores 
Tabela A.2: Coalizões Possíveis entre as Regiões Brasileiras - Sistema Atual

\begin{tabular}{|c|c|c|c|c|c|}
\hline Coalizões & Peso & Resultado & Coalizões & Peso & Resultado \\
\hline 0 & 0 & 0 & $\mathrm{~N}, \mathrm{Ne}, \mathrm{S}$ & 293 & 1 \\
\hline $\mathrm{N}$ & 65 & 0 & $\mathrm{~N}, \mathrm{Ne}, \mathrm{Se}$ & 395 & 1 \\
\hline $\mathrm{Ne}$ & 151 & 0 & $\mathrm{~N}, \mathrm{Ne}, \mathrm{Co}$ & 257 & 1 \\
\hline S & 77 & 0 & $\mathrm{~N}, \mathrm{~S}, \mathrm{Se}$ & 321 & 1 \\
\hline Se & 179 & 0 & N,S,Co & 183 & 0 \\
\hline Co & 41 & 0 & N,Se,Co & 285 & 1 \\
\hline $\mathrm{N}, \mathrm{Ne}$ & 216 & 0 & $\mathrm{Ne}, \mathrm{S}, \mathrm{Se}$ & 407 & 1 \\
\hline $\mathrm{N}, \mathrm{S}$ & 142 & 0 & $\mathrm{Ne}, \mathrm{S}, \mathrm{Co}$ & 269 & 1 \\
\hline $\mathrm{N}, \mathrm{Se}$ & 244 & 0 & $\mathrm{Ne}, \mathrm{Se}, \mathrm{Co}$ & 371 & 1 \\
\hline $\mathrm{N}, \mathrm{Co}$ & 106 & 0 & $\mathrm{~S}, \mathrm{Se}, \mathrm{Co}$ & 297 & 1 \\
\hline $\mathrm{Ne}, \mathrm{S}$ & 228 & 0 & $\mathrm{~N}, \mathrm{Ne}, \mathrm{S}, \mathrm{Se}$ & 472 & 1 \\
\hline $\mathrm{Ne}, \mathrm{Se}$ & 330 & 1 & $\mathrm{~N}, \mathrm{Ne}, \mathrm{S}, \mathrm{Co}$ & 334 & 1 \\
\hline $\mathrm{Ne}, \mathrm{Co}$ & 192 & 0 & $\mathrm{~N}, \mathrm{Ne}, \mathrm{Se}, \mathrm{Co}$ & 436 & 1 \\
\hline S,Se & 256 & 0 & $\mathrm{~N}, \mathrm{~S}, \mathrm{Se}, \mathrm{Co}$ & 362 & 1 \\
\hline S,Co & 118 & 0 & $\mathrm{Ne}, \mathrm{S}, \mathrm{Se}, \mathrm{Co}$ & 448 & 1 \\
\hline $\mathrm{Se}, \mathrm{Co}$ & 220 & 0 & $\mathrm{~N}, \mathrm{Ne}, \mathrm{S}, \mathrm{Se}, \mathrm{Co}$ & 513 & 1 \\
\hline
\end{tabular}

Fonte: elaboração própria.

Tabela A.3: Coalizões Possíveis entre as Regiões Brasileiras - Sistema Proposto

\begin{tabular}{|c|c|c|c|c|c|}
\hline Coalizões & Peso & Resultado & Coalizões & Peso & Resultado \\
\hline 0 & 0 & 0 & $\mathrm{~N}, \mathrm{Ne}, \mathrm{S}$ & 56,55 & 1 \\
\hline $\mathrm{N}$ & 13,09 & 0 & $\mathrm{~N}, \mathrm{Ne}, \mathrm{Se}$ & 69,3 & 1 \\
\hline $\mathrm{Ne}$ & 25,19 & 0 & $\mathrm{~N}, \mathrm{Ne}, \mathrm{Co}$ & 50,71 & 0 \\
\hline$S$ & 18,27 & 0 & $\mathrm{~N}, \mathrm{~S}, \mathrm{Se}$ & 62,38 & 1 \\
\hline Se & 31,02 & 0 & N,S,Co & 43,79 & 0 \\
\hline Co & 12,43 & 0 & N,Se,Co & 56,54 & 1 \\
\hline $\mathrm{N}, \mathrm{Ne}$ & 38,28 & 0 & $\mathrm{Ne}, \mathrm{S}, \mathrm{Se}$ & 74,48 & 1 \\
\hline $\mathrm{N}, \mathrm{S}$ & 31,36 & 0 & $\mathrm{Ne}, \mathrm{S}, \mathrm{Co}$ & 55,89 & 1 \\
\hline $\mathrm{N}, \mathrm{Se}$ & 44,11 & 0 & $\mathrm{Ne}, \mathrm{Se}, \mathrm{Co}$ & 68,64 & 1 \\
\hline N,Co & 25,52 & 0 & $\mathrm{~S}, \mathrm{Se}, \mathrm{Co}$ & 61,72 & 1 \\
\hline $\mathrm{Ne}, \mathrm{S}$ & 43,46 & 0 & $\mathrm{~N}, \mathrm{Ne}, \mathrm{S}, \mathrm{Se}$ & 87,57 & 1 \\
\hline $\mathrm{Ne}, \mathrm{Se}$ & 56,21 & 1 & $\mathrm{~N}, \mathrm{Ne}, \mathrm{S}, \mathrm{Co}$ & 68,98 & 1 \\
\hline $\mathrm{Ne}, \mathrm{Co}$ & 37,52 & 0 & $\mathrm{~N}, \mathrm{Ne}, \mathrm{Se}, \mathrm{Co}$ & 81,73 & 1 \\
\hline S,Se & 49,29 & 0 & N,S,Se,Co & 74,81 & 1 \\
\hline S,Co & 30,67 & 0 & $\mathrm{Ne}, \mathrm{S}, \mathrm{Se}, \mathrm{Co}$ & 86,91 & 1 \\
\hline Se,Co & 43,45 & 0 & $\mathrm{~N}, \mathrm{Ne}, \mathrm{S}, \mathrm{Se}, \mathrm{Co}$ & 100 & 1 \\
\hline
\end{tabular}

Fonte: elaboração própria. 


\section{Referências Bibliográficas}

Algaba, E., Bilbao, J. M., García, J. R. F. \& López, J. J. (2001), 'El Índice de poder de banzhaf en la unión europea ampliada', Quaderns d'Estatística i Investigació Operativa 25, 71-90.

Araújo, T. B. (2000), Ensaios sobre o Desenvolvimento Brasileiro: heranças e urgências, Revan.

Bilbao, J. M., García, J. R. F., Jiménez-losada, A. \& Lópes, J. J. (2000), 'Generating functions for computing power indices efficiently', TOP 8, 191-213.

Jatobá, A. D. S. C. \& Ramos, F. S. (2003), Regiões brasileiras e representatividade na câmara dos deputados no período 1945-1998: a disputa por recursos, in 'VIII Encontro Regional de Economia'.

Novaes, A. \& Rosenblatt, D. (1991), 'A note on regional voting power and budget allocation in the brazilian congress', Revista Brasileira de Economia $45,313-324$.

Zyczkowski, K. \& Stomczunski, W. (2004), Voting in the european union: the square root system of penrose and a critical point, Technical report, Jagielonian University. 